\title{
Institutional and External Assistance to Cope Climatic Shocks: a case study from Barpak village of Gorkha District.
}

\author{
Narayan Prasad Gautam ${ }^{1}$, Pengfei Wu ${ }^{2}$, Nirjala Raut ${ }^{3}$ \\ ${ }^{1}$ Institute of Forestry, Tribhuvan University, Pokhara Nepal, Fujian Agriculture \\ and Forestry University, China - PhD Student \\ ${ }^{2}$ Fujian Agriculture and Forestry University, China. \\ ${ }^{3}$ Institute of Forestry, Tribhuvan University, Pokhara Nepal
}

\begin{abstract}
This paper is based on the case study which was carried out to investigate post institutional and external support to hazard events in Barpak village of Gorkha district. Primary data were collected from household survey where one hundred households were interviewed using structured schedule. An economic stratum of the household was used as variables for the study. Sampled households were categorized into three sub strata i.e. rich, medium and poor. More or less equal number of each stratum participated in household survey. Simple descriptive statistics was used for data analysis where percentage, weighted mean were used to interpret the results. Perceptions of the sampled households were tested with independent chisquare. Result shows that media plays an important role to disseminate about the knowledge on climate change and associated impacts in the villagers. Climate change information, loan as well as donation for coping to climate variability and technical know-how are the major support that people obtained in the village for coping climatic hazards. Poor villagers are almost dissatisfied with almost all supports experiencing while coping against climatic hazards than that of rich and medium strata family of the village.
\end{abstract}

Key words: Shocks, climate change, external support, adaptation to shock, Nepal Himalaya

\section{Introduction}

Nepal is an agrarian country and identified as a vulnerable country to climate change. The immediate observed impact of climate change is melting of Himalayan glaciers at higher rate. The studies have shown that the temperature of Nepal has also been increasing more prominently in higher altitudes compared to lower altitudes (Shrestha et al., 1999). Increase in atmospheric temperature would cause vulnerability due to decrease in water table, increase in evapo-transpiration, reduction of soil fertility, while increase in intensity of rainfall would cause soil erosion, landslides and floods, and inundation of standing crops.

Most of the mountain communities in Nepal largely depend up on surrounding bio-physical system for obtaining their livelihood (Epstein et al., 2018). Agriculture, forestry, animal husbandry and small trades are major sources of household economy of mountain people (Gurung 2007). Under the circumstances of widespread poverty, illiteracy, political ignorance, marginalized settlements and fragile environment, the sources of 
livelihood for mountain people are becoming extremely vulnerable (Lama and Devkota, 2009). Indeed, in the context of high-rate of climate change and its large consequences, mountain people are considered more vulnerable than any other communities in the globe. Along this, the impacts of climate change hit the poor the hardest because they have comparatively least alternatives for mitigating the climatic shocks (Hallegatte et al., 2015).

Before taking any effective action against climate change impact at community level it is essential to know the vulnerability level of particular community. If we identify the major aspects of vulnerability and its magnitude for a particular community, it will help in assessing the degree of sustainability of livelihoods that community owns. The major problem is lack of proper information, adequate relief materials to cope experienced shocks. It is hard to make community more resistant in absence of appropriate assistance and relevant information regarding appropriate knowledge and skill to adapt over climatic shocks (Alexander, 2015).

The lack of broad public support for climate change mitigation policy hampers efforts to adopt timely approaches to the climate crisis. Lu and Schuldt (2016) concluded that climate-related humanitarian crisis was caused by human activities. That's why it is the responsibility of human and their organization to help those who are struggling from climatic shocks. The various types of disasters can be interconnected. People in the aftermath of massive disaster can cooperate to survive. Climate is changing rapidly and it is no longer possible to predict both immediate and longer term planetary conditions (Bosy et al., 2010), but what is clear is that an increasing number of people will be forced to adapt and build resilience to the impacts of climate change whether or not they have the economic, social, and personal resources to do so. When countries face natural disasters such as forest fires, floods, earthquakes and other climatic shocks or are in need of emergency assistance due to other crises, there are several institutions that have a range of funding and emergency response to help. Fairness has recently become a key concern for crisis managers. In the aftermath of a disaster, when needs overcome response's capacity, decision makers are expected to distribute the available relief efficiently, but also in such a way that nobody might perceive any justice in the access to relief (AnayaArenas et al., 2016). The major challenge is; to what extent the distributed relief is fair? It is urgent to raise a question in order to establish the fair relief distribution system. In this arena, this paper tries to explore the satisfaction status of climate change victims on received assistance from different sources.

\section{Methods and materials:}

The study was concentrated in all wards of Barpak area of Gorkha district. One hundred households were selected for carrying out the interview where one third households from each economic classed households i.e. rich, medium and poor. Along this, village meeting was also organized to discuss about various source of information to climate change and their effectiveness to adapt the suitable climate change coping strategies. 
The Simple statistical tools like percentage and arithmetic mean (response mean or weighted mean), were used to interpret the data where table and figures were used for presenting the results. Perceptions were tested using chi-square test (independent) where 5 percent $(\mathrm{Alfa}=0.05)$ level of significance was used.

\section{Results and discussions:}

Information obtained about climate, climate change and its use to prepare/cope in case of climate variability or hazards

According to the village meeting, it was explored that there were various sources of information on climate change and its impacts along the coping strategies in the village but people were not so aware on channel to get information and it was found that trend of getting climate related information in the village was very few.

In household survey, it was found that the people were not so aware about the information to cope up with the future climatic hazards. $31.6 \%$ information regarding the climate change and its impacts were obtained from own observation by Barpak's people where majority of the respondents reported that they have used these information to prepare/cope in case of climate variability or hazards in the area.

Table 1: Information sources available to respondents

\begin{tabular}{|c|c|c|c|}
\hline \multirow[t]{2}{*}{ Information source } & \multirow{2}{*}{$\begin{array}{l}\text { Share of } \\
\text { information } \\
\text { obtained }(\%)\end{array}$} & \multicolumn{2}{|c|}{$\begin{array}{c}\text { Response in information used for planning } \\
\text { of own work }(\%)\end{array}$} \\
\hline & & Yes & No \\
\hline Media & 25.8 & 24.56 & 75.44 \\
\hline Education & 10.3 & 61.90 & 38.10 \\
\hline Family & 7.2 & 73.30 & 26.70 \\
\hline Friends & 9.4 & 36.84 & 63.16 \\
\hline Own observations/feel & 31.6 & 56.41 & 43.59 \\
\hline Meteorological station & 1.0 & 33.33 & 66.67 \\
\hline NGOs & 0.5 & 0.00 & 100 \\
\hline Outside experts & 1.0 & 66.67 & 33.33 \\
\hline Villagers & 13.2 & 89.29 & 10.71 \\
\hline
\end{tabular}

Likewise, $25.8 \%, \quad 13.2 \%$ and $10.3 \%$ information that they have obtained from media, villagers and education (formal or informal education in the area) respectively where $89.29 \%$ respondents were using the information obtained from villagers to cope up in case of climate variability. It reveals that own observation and media were the major source of information to the villagers in the area about understanding climate change. Likewise, villagers, family and friends also have been supporting to understand the climate and its variability in the area. Kakade et al. (2013) concluded the same. They found that the media is major means to inform the climate change and its effects to the human beings esp. to the people who are living remote areas. 


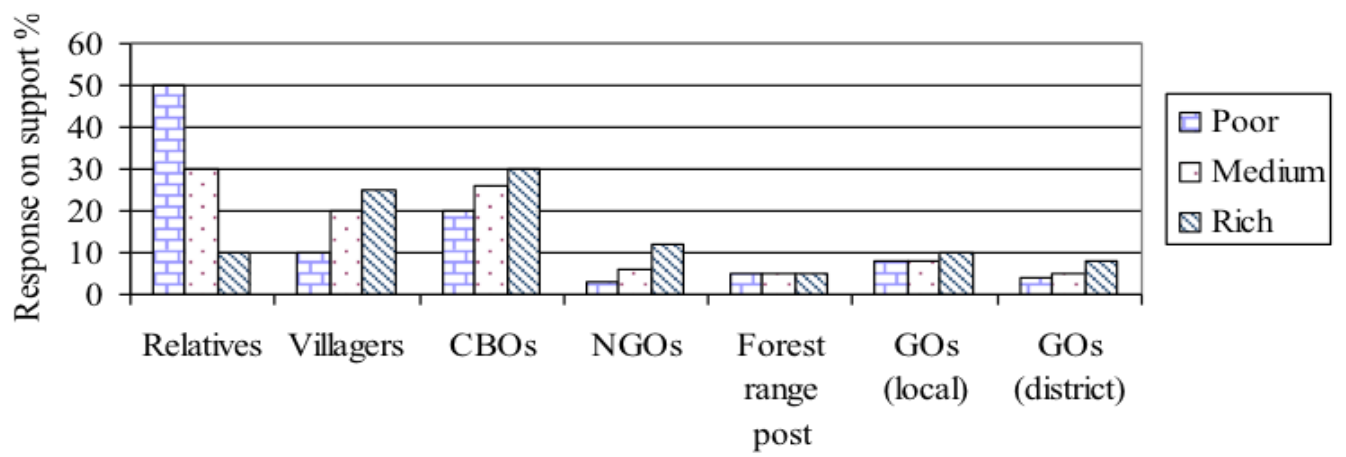

Support from

Figure 1: Support from different sources to household for coping climatic hazards

Majority of the poor respondents (around $50 \%$ ) and medium wealth strata respondents $(30 \%)$ reported that they received the support to cope up with the hazard from their relatives. But majority of the rich respondents $(30 \%)$ reported that they received the support from villagers (around $25 \%$ ). From the figure, it was concluded that the Barpak village did not get adequate support from other government or nongovernment organization working for the village development. Remarkable supports were from relatives, villagers or community

\section{Respondent's satisfaction on received different types of support for coping climatic hazards.}

The overall figure depicts that rich are satisfied with different types of support for coping climatic hazards while medium are based organization such as occupational groups, mother groups and saving groups. In an average poorer household were not obtaining adequate assistance from organizations and any other relief distributing institution in the study area. Same findings were reported by the World Bank (2002), they had mentioned many sectors providing basic livelihood services to the poor as reief are not sufficient and not able to cope with climate variability and stresses.

in neutral condition with dissatisfaction in some supports and poor are almost dissatisfied or unsatisfied with almost all supports experiencing while fighting against climatic hazards.

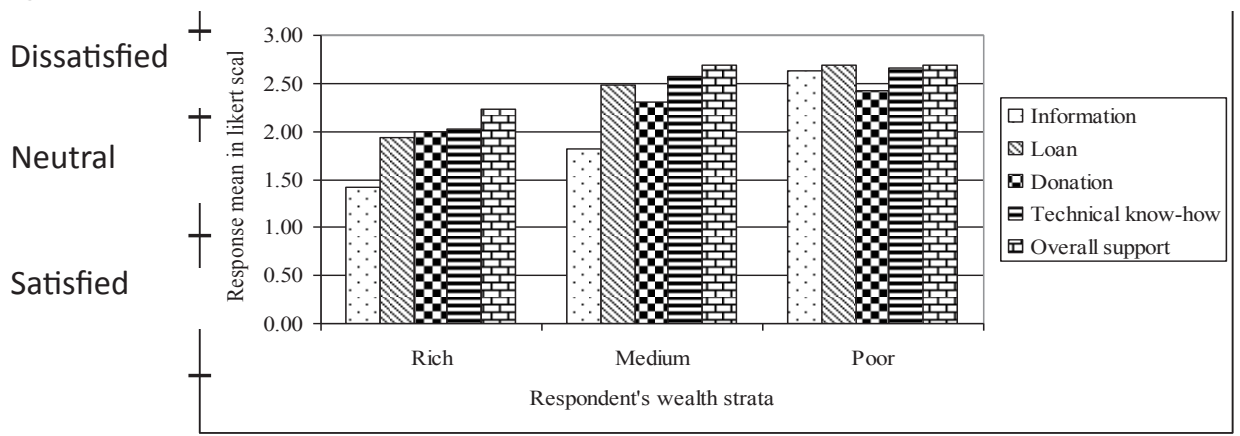

Figure 2: Respondent's satisfaction on received different types of support for coping climatic hazards 
Rich are more satisfied with the information as a source of support for coping hazards since rich people have different source of information like television, mobile, participating in different events from which they receive quick information. Medium are much more neutral towards information as a source of support and poor are dissatisfied with the information as a source of support as they have limited source to get information regarding this.

Reasons of not being dissatisfied by the rich respondents with major four supports available in the village were they did not fully dependent on outside support for coping up the hazards. Also relatively they did not feel the climate change reaction, was big or serious. But poor respondents were found dissatisfied with all supports i.e. information, loan, donation and technical know-how because they did not have other alternative to cope up climate variability where they had to fully dependent upon those supports but whatever they received were not adequate. Beside these, support received by poor did not help as their expectation for mitigating the shocks brought by climate change in the area. Raleigh et al. (2008) found the similar findings that poorer family have lesser alternatives for living than that of wealth off and what they obtain in the name of disaster relief cannot fully overcome their shocks.

\section{Respondent's perception on various support received to hazards events}

Rich respondents agreed (weighted mean 1.41) on the statement "received climate change related information were adequate and supportive" while Medium were neutral (1.82) and Poor were found disagree on the statement. While testing the hypothesis (Ho) i.e. perception on the statement among the respondent's category is not significantly different, using chisquare independent test, it was found that the sated hypothesis was rejected ( $p 0.000)$. It means perception were significantly different among rich, medium and poor.

Table 2: Perception on received CC related information

\begin{tabular}{llll}
\hline $\begin{array}{l}\text { Respondent's } \\
\text { category }\end{array}$ & $\begin{array}{l}\text { Weighted } \\
\text { mean of } \\
\text { response }\end{array}$ & $\begin{array}{l}\text { Chi- } \\
\text { square }\end{array}$ & $\begin{array}{l}\text { p- } \\
\text { value }\end{array}$ \\
\hline Rich & 1.41 \\
\cline { 1 - 2 } Medium & 1.82 & & \\
\hline Poor & 2.64 & & \\
\hline
\end{tabular}

Poor respondents disagreed (weighted mean 2.70) on the statement "loan taking was not comfortable and easy" whereas medium and rich were found neutral on the statement. While testing, it was found perception among the rich, medium and poor on the statement was significantly different.

Table 3: Perception on getting loan for coping climatic hazards

\begin{tabular}{llll}
\hline $\begin{array}{l}\text { Respondent's } \\
\text { category }\end{array}$ & $\begin{array}{l}\text { Weighted } \\
\text { mean of } \\
\text { response }\end{array}$ & $\begin{array}{l}\text { Chi- } \\
\text { square }\end{array}$ & $\begin{array}{l}\text { p- } \\
\text { value }\end{array}$ \\
\cline { 1 - 2 } Rich & 1.94 & 29.511 & $.000^{*}$ \\
\cline { 1 - 2 } Medium & 1.48 & & \\
\cline { 1 - 2 } Poor & 2.70 & & \\
\hline
\end{tabular}

$\downarrow 0-1.50=$ Agree, $1.51-2.50=$ Neutral,

2.51-3.0=Disagree

$\mathrm{P} *$ indicate significant at $5 \%$ level of significance 
Although the all respondents were found neutral (rich 2.00, medium 2.30 and poor 2.42 weighted mean) on the statement "donation received were adequate and supportive" perception on the statement among respondent's category was significantly different". The result concur that how much they received was not adequate for coping/adapting the changes but they became happy to get donation (not need to return).

Table 4: Perception on donation received for coping climatic hazards

\begin{tabular}{llll}
\hline $\begin{array}{l}\text { Respondent's } \\
\text { category }\end{array}$ & $\begin{array}{l}\text { Weighted } \\
\text { mean of } \\
\text { response }\end{array}$ & $\begin{array}{l}\text { Chi- } \\
\text { square }\end{array}$ & $\begin{array}{l}\text { p- } \\
\text { value }\end{array}$ \\
\cline { 1 - 2 } Rich & 2.00 & 27.043 & $.000^{*}$ \\
\cline { 1 - 2 } Medium & 1.30 & & \\
\hline Poor & 2.42 & & \\
\hline
\end{tabular}

It was revealed that poor (weighted mean 2.67) and medium (weighted mean 2.58) respondents were not happy with the technical know-how available to them for coping the climatic hazards whereas rich were found neutral. It is due to the reasons that rich household have more access and alternatives towards such types of information and knowledge. It means rich were lesser dependents to the direct outsider supports on technical know-how against climatic hazards. In testing hypothesis, it was rejected. It means perception on the statement "technical know-how obtained was fruitful for coping climatic hazards" among the rich, medium and poor were significantly different.

Table 5: Perception on technical know-how obtained for coping climatic hazards

\begin{tabular}{llll}
\hline $\begin{array}{l}\text { Respondent's } \\
\text { category }\end{array}$ & $\begin{array}{l}\text { Weighted } \\
\text { mean of } \\
\text { response }\end{array}$ & $\begin{array}{l}\text { Chi- } \\
\text { square }\end{array}$ & $\begin{array}{l}\text { p- } \\
\text { value }\end{array}$ \\
\cline { 1 - 2 } Rich & 2.03 & 22.919 & $.000^{*}$ \\
\cline { 1 - 2 } Medium & 2.58 & & \\
\cline { 1 - 2 } Poor & 2.67 & & \\
\hline
\end{tabular}

It was found that medium and poor wealth category of the respondents disagreed where weighted mean of responses were 2.7 and 2.7 respectively, on the statement "received overall support from community or institutions were adequate and satisfactory". But rich were found neutral.

Table 6: Perception on satisfaction on received overall support from community or institutions

\begin{tabular}{llll}
\hline $\begin{array}{l}\text { Respondent's } \\
\text { category }\end{array}$ & $\begin{array}{l}\text { Weighted } \\
\text { mean of } \\
\text { response }\end{array}$ & $\begin{array}{l}\text { Chi- } \\
\text { square }\end{array}$ & $\begin{array}{l}\text { p- } \\
\text { value }\end{array}$ \\
\hline Rich & 2.24 & 22.320 & $.000^{*}$ \\
\hline Medium & 2.70 & & \\
\hline Poor & 2.70 & & \\
\hline
\end{tabular}

While testing the data with independent chi-square, perception among the rich, medium and poor were significant different. It reveals that the range of satisfaction of people on the institutions and other community support to fight against climatic hazards were not same in the area.

\section{Conclusion}

Primarily, people perceived the climate change by their own observation. Along this, media play important role to disseminate about the knowledge on climate change and associated impacts in the villagers. Beside these, villagers, family, friends have been supporting them to understand the climate and its variability as well as techniques of adaptation to climate change in the area.

$\downarrow 0-1.50=$ Agree, $1.51-2.50=$ Neutral,

2.51-3.0=Disagree

$\mathrm{P} *$ indicate significant at $5 \%$ level of significance 
Climate change information, loan as well as donation for coping to climate variability and technical know-how are the major support that people obtained in the village for coping climatic hazards. Remarkable support that people receive to cope up the climatic hazards in the village from relatives, villagers or community based organization such as occupational groups, mother groups, saving groups, etc. The support that they have been getting is not adequate to cope and adapt the shocks. Rich are more or less satisfied with different types of support for coping climatic hazards while medium are in neutral condition with dissatisfaction in some supports and poor are almost dissatisfied or unsatisfied with almost all supports experiencing while fighting against climatic hazards.

\section{Reference}

Alexander, D.E. 2015. Disaster and Emergency Planning for Preparedness, Response, and Recovery. Oxford University Press, 2015: 1-20.

Anaya-Arenas, A.M., Ruiz, A. And Renauld, J. 2016. Models for a Fair Humanitarian Relief Distribution. CIRRELT report. Canada. Accessed on 12th November 2016 at https://www. cirrelt.ca/Documents Travail/ CIRRELT-2016-11.pdf.

Bosy, J., Rohm, W., Borkowski, A., Kroszczynski, K. and Figurski, M. 2010. Integration and Verification of Meteorological Observations and NWP Model Data for the Local GNSS Tomography. Atmos Res 95:255-269. doi:10.1016/j. atmosres.2009.12.012
Reasons of not being dissatisfied by the rich respondents with supports available and use in the village are they do not fully dependent on outside support for coping up the hazards. Relatively they do not feel the climate change reaction, is big or serious because they have other earnings alternatives. But poor respondents dissatisfy with all supports i.e. information, loan, donation and technical know-how because they do not have other alternative to cope up climate variability where they have to fully dependent upon those supports. Also, support received by poor is not helping them as per their expectation for mitigating the shocks brought by climate change in the area.

Epstein, K., Dicarlo, J., Marsh, R., Adhikari, B.J Poudel, D., Ray, I. and Maren, E. 2018. Recovery and Adaptation After the 2015 Nepal Earthquakes: a Smallholder Household Perspective. Ecology and Society 23 (1): 29.

Gurung, H. 2007. Bisaya Bividh (in Nepali). Himal Kitab, Kathmandu.

Hallegatte, S., Bangalore, M., Bonzanigo, L., Fay, M., Kane, T., Narloch, U., Rozenberg, J., Treguer, D. and Vogt-Schilb, A., 2015. Shock waves: managing the impacts of climate change on poverty. The World Bank.

Kakade, O., Hiremath, S. and Raut, N. 2013. Role of Media in Creating Awareness about Climate Change- A Case Study of Bijapur City. Journal Of Humanities And 
Social Science. 10(1):37-43.

Lama, S. and Devkota, B. 2009. Vulnerability

of Mountain Communities to Climate Change and Adaptation Strategies. The Journal of Agriculture and Environment. 10:76-83.

Lu, H. and Schuldt, J.P. 2016. Compassion for Climate Change Victims and Support for Mitigation Policy. Journal of Environmental Psychology. 45:192-200.

Shrestha, A.B., Wake, C.P., Mayewski, P.A. and Dibb, J.E. 1999. Maximum Temperature Trends in the Himalaya and its Vicinity: An Analysis Based on Temperature Records from Nepal for the Period 1971-94. Journal of climate. 12:2775-2789.

World Bank. 2002. Poverty and Climate Change Reducing the Vulnerability of the Poor through Adaptation. A report prepared for presenting Eighth Conference of Parties to the United Nations Framework Convention on Climate Change in New Delhi. Accessed on 2nd April 2017at http://www.oecd. org/env/cc/2502872.pdf. 